\title{
PHENOTYPIC AND GENOTYPIC CHARACTERIZATION OF STREPTOCOCCUS UBERIS ISOLATED FROM MASTITIC COW'S MILK
}

\author{
HANAA A.E. ASFOUR ${ }^{1}$, SAMAH F. DARWISH ${ }^{2}$ and SAFAA A. EL-WAKEEL ${ }^{1}$ \\ ${ }^{1}$ Mastitis and Neonatal Diseases Department, Animal Reproduction Research Institute (ARRI), Giza, Egypt \\ ${ }^{2}$ Biotechnology Research Unit, Animal Reproduction Research Institute (ARRI), Giza, Egypt
}

Received: 26 September 2016; Accepted: 17 October 2016

\begin{abstract}
A total number of 240 milk samples was collected from clinical (88 quarter milk samples; QMS), subclinical (108 QMS) and bulk tank (44 BTM) cow's milk selected from different dairy farms for detection of some phenotypic virulence factors and some putative virulence associated genes by polymerase chain reaction (PCR) in the isolated $S$. uberis strains. Also detection of antibiotic resistance for the isolated strains using conventional assay was applied. Using biochemical tests and molecular assay, the confirmed S. uberis strains was 48 out of 74 Streptococcus species $(64.9 \%)$. The $\%$ of S. uberis isolation from the total examined milk samples was $20 \%$. The higher $S$. uberis incidence was detected in bulk tank milk samples $(45.5 \%)$ followed by clinical and subclinical milk samples (18.2\% and $11.1 \%$, respectively). In studying the phenotypic virulence factors of the collected $S$. uberis isolates, it was found that $\beta$-haemolysis and positive CAMP factor like reaction were detected in only $6.25 \%$ of $S$. uberis isolates for each of them, while slime production as indicator for biofilm formation was detected in $75 \%$ of these isolates. A total of 48 isolates was tested for their in vitro antimicrobial sensitivity. Some of the isolates were highly sensitive to a limited number of antibiotics. On the other hand, the majority of the isolates were highly resistant to a large number of other antibiotics. In studying the genotypic virulence genes, gapC gene was detected in all the isolated strains of $S$. uberis while oppF, cfu and sau genes were detected in $93.8 \%, 68.8 \%$ and $62.5 \%$, respectively. On the contrary, $l b p$ gene couldn't be detected in any of the isolated strains of $S$. uberis. At least 2 of the five different virulence genes were detected in each isolate of $S$. uberis. There were some strains harboring 4 virulence genes and the higher rate of these strains was detected in that isolated from clinical mastitis. Moreover, the higher strains harboring 3 virulence genes were detected in that isolated from subclinical mastitis. In conclusion, it was observed that $S$. uberis should be given a great concern as a threat for the dairy cows. As it caused both clinical and subclinical mastitis as well as it was isolated with high percentage in BTM. Moreover, this pathogen nowadays emerges as resistance to different antimicrobial agents especially for those commonly utilized. Furthermore, S. uberis harbors different virulence factors and genes that capable it to persist in the mammary gland of the dairy animals for a long time and speeding of infection from cow to cow may occur resulting in higher prevalence rates of infection between different dairy farms.
\end{abstract}

Key words: S. uberis mastitis; haemolysis; CAMP; biofilm; antimicrobial sensitivity; PCR assays; virulence genes.

\section{INTRODUCTION}

Mastitis caused by Streptococcus uberis has been detected increasingly in dairy farms over the last decades. Infection with some strains can induce mild subclinical inflammation whilst others induce severe inflammation and clinical infections of the bovine udder. It represents the leading pathogen in a growing amount of dairy herds (Kromker et al., 2014 and Günther et al., 2016).

Corresponding author: Dr. HANAA A.E. ASFOUR

E-mail address: hanaaasfour@yahoo.com

Present address: Mastitis and Neonatal Diseases Department, Animal Reproduction Research Institute (ARRI), Giza, Egypt
Coagulase negative staphylococci, S. uberis and $S$. dysgalactiae are considered to be both contagious and environmental pathogens (Taponen and Pyorala, 2006). S. uberis pathogen is ubiquitous for which it is considered as environment-associated. Not only straw bedding and pasture, but also the bovine skin and digestive mucosae are typical localizations inhabited by $S$. uberis. Due to its capacity to persist within the mammary tissue, some infections may eventually turn cow-associated. In other cases, the infection was short, but in any case, there was a high risk of reinfection. Although many varieties remained susceptible to most antimicrobial agents, the problem for the dairy farm lied in the high rate of re-infection (Kromker et al., 2014). It should be concluded that $S$. uberis caused the increase in total bacteria count, 
somatic cell count (SCC) and the decrease in $\kappa$-casein level, which significantly affects the technological quality of cows' milk (Pecka-Kiełb et al., 2016).

S. uberis is an important pathogen that has been implicated in bovine mastitis but the virulence factors associated with pathogenesis are not well understood (Reinoso et al., 2011). Others, however, have proposed numerous virulence traits that may be associated with the ability of $S$. uberis to cause mastitis as the ability to form biofilm (Varhimo et al., 2011).

Molecular diagnostic methods revealed that S. uberis may be subdivided into many different varieties with different epidemiological properties (Kromker et al., 2014). Despite the severe economic impact caused by the high prevalence of $S$. uberis in many wellmanaged dairy herds, virulence factors associated with pathogenesis were not well understood and constituted a major obstacle for the development of strategies to control this important mastitis pathogen (Oliver et al., 1998). Several putative virulence associated genes of $S$. uberis have been described. Among these, lactoferrin binding proteins (Moshynskyy et al., 2003), adherence to and invasion of epithelial cells mediated by $S$. uberis specific adhesion molecule (SUAM) (Almeida et al., 2006), CAMP factor (Jiang et al., 1996), a surface dehydrogenase protein gapC (Pancholi and Fischetti, 1993) and opp proteins involved in the active transport of solutes essential for growth in milk (Smith et al., 2002) have been found.

The aim of this work was to determine the incidence rate of $S$. uberis infection in both mastitic cows and bulk tank milk of different dairy farms based on both phenotypic and genotypic assays. Also, detection of some phenotypic virulence characteristics and some putative virulence associated genes in the isolated $S$. uberis strains were performed. Additionally, antibiotic susceptibility of the isolated $S$. uberis strains was investigated using disk diffusion method.

\section{MATERIALS AND METHODS}

\section{A- Collection of milk samples:}

Total number of 240 milk samples; included 88 QMS collected from clinical mastitic cows, 108 QMS collected from subclinical mastitic cows and 44 BTM samples, were included in the present study. The quarter milk samples were collected from a single visit at milking time at the farms using physical examination and California mastitis test (CMT). Samples were subjected to somatic cell count (SCC) in order to confirm the subclinical status of mastitis (> 250,000 cells $/ \mathrm{ml}$ ) of the collected samples using the Nucleocounter SCC-100 (Chemometric Nucleocounter Family, Denmark) (Lasagno et al., 2011).
B- Bacteriological isolation: One standard loop of milk samples was streaked on 7\% sheep blood agar, Edward's media, macConkey agar and mannitol salt agar (Himedia, Mumbai, India). The inoculated plates were incubated aerobically at $37^{\circ} \mathrm{C}$. The plates were checked for growth after 24-48h. Primary identification of Streptococci especially $S$. uberis was based on colony size, shape, colour, haemolytic characteristics, Grams reaction and catalase test (Quinn et al., 2011).

\section{C- Phenotypic characterization of $S$. uberis: \\ 1- Colony characteristic on Edward's media as selective medium for $S$. uberis:}

Colonies that were primary identified as Streptococci were streaked on Edward's media plates as a selective medium, incubated at $37^{\circ} \mathrm{C}$ and examined after $24-48$ $\mathrm{h}$ for growth and change in colour of the medium. The presence of growth, haemolysis and esculin hydrolysis (dark background) were indications of $S$. uberis. Then, colonies which grew on Edward's media were picked and streaked on macConkey agar. The absence of growth on macConkey agar was an indication of $S$. uberis. The isolates were initially identified using standard conventional biochemical tests according to Quinn et al. (2011). Since $S$. uberis is a fastidious bacterium, so it was sub-cultured on brain heart infusion agar for further PCR assays.

\section{2- Detection of slime production by Congo red agar method.}

Slime production as an indicator for biofilm formation was evaluated by cultivation of $S$. uberis isolates on Congo red agar (CRA) plates as described by Mathur et al. (2006). Isolates were interpreted according to their colony phenotypes. Black colonies with dry consistency and rough surface and edges were considered a positive indication of slime production, while both black colonies with smooth, round and shiny surface and red colonies with dry consistency and rough edges and surface were considered as intermediate slime producers. Red colonies with smooth, round, and shiny surface were indicative of negative slime production.

\section{3- CAMP factor like reaction:}

Bacteria were screened for CAMP factor activity as previously described by Jiang et al. (1996). Briefly, $S$. uberis strains were streaked perpendicular to a streak of $\beta$-haemolytic $S$. aureus on blood agar plates and after $6-20 \mathrm{~h}$ incubation at $37^{\circ} \mathrm{C}$, they were observed for haemolysis.

\section{4- Antibiotic susceptibility testing of the isolated $S$. uberis:}

Antimicrobial susceptibility of S. uberis strains to 14 antibiotics using Disk diffusion technique was performed according to the National Committee for Clinical Laboratory Standards (NCCLS, 2008) on Mueller Hinton agar (Himedia, Mumbai, India) using commercially available antimicrobial test discs [ciprofloxacin; CIP $(5 \mu \mathrm{g})$, norfloxacin; NOR $(10 \mu \mathrm{g})$, 
florfenicol FFC $(15 \mu \mathrm{g})$, chloramphenicol; C (30 $\mu \mathrm{g})$, amoxicillin-clavulanic acid; AMC $(30 \mu \mathrm{g})$, amoxicillin; AMX $(25 \mu \mathrm{g})$, ampicillin; AM $(10 \mu \mathrm{g})$, penicillin; $\mathrm{P}(10 \mathrm{U})$, tetracycline; TE $(30 \mu \mathrm{g})$, neomycin; N $(30 \mu \mathrm{g})$, erythromycin; E $(15 \mu \mathrm{g})$, streptomycin; S $(10 \mu \mathrm{g})$, cloxacillin; CX $(1 \mu \mathrm{g})$ and oxacillin; OX $(1 \mu \mathrm{g})]$. Results were recorded by measuring the inhibition zones and scored as sensitive, intermediate susceptibility and resistant according to the NCCLS recommendations.

\section{C- Genotypic characterization of $S$. uberis:}

1. DNA extraction from Streptococcus isolates:

Crude DNA template was prepared by boiling followed by snap chilling into ice according to method previously reported by Asfour and Darwish
(2011). Briefly, the colonies grown over the surface of brain heart agar plates were harvested and washed twice by phosphate buffer saline. A small quantity of bacterial pellets was dissolved in $200 \mu \mathrm{l}$ TE buffer (10 mM Tris, 1mM EDTA pH 7.6) and boiled in a boiling water bath for about $10 \mathrm{~min}$ and then immediately snap chilled into ice. A centrifugation step was followed at $8000 \mathrm{rpm}$ for $10 \mathrm{~min}$. to sediment debris while the supernatant was aspirated and kept at $-20^{\circ} \mathrm{C}$ until time for PCR. Five microliters of this lysate was used as a template in PCR assays.

\section{Primers:}

Different primers were used in this study. Primer sequences, their references, product sizes and annealing temperatures are listed in table 1 .

Table 1: Primers used in the study, their nucleotide sequences, species specific, references, Annealing temperatures $\left(\mathrm{T}_{\mathrm{a}}\right)$ and their PCR products sizes.

\begin{tabular}{|c|c|c|c|c|}
\hline $\begin{array}{l}\text { Primer } \\
\text { name }\end{array}$ & $\begin{array}{c}\text { Sequence 5'-3' } \\
\text { (reference) }\end{array}$ & Target taxon/gene & $\mathrm{T}_{\mathrm{a}}^{\circ} \mathrm{C}$ & $\begin{array}{l}\text { Product } \\
\text { size bp }\end{array}$ \\
\hline St F & 5' TTATGCTCGTCTTGCTCTTTACGG 3' & Genus Streptococcus & 58 & $281 \mathrm{bp}$ \\
\hline St R & 5' GCACACGTCCAAGTGATGTAGCTG 3' & & & \\
\hline
\end{tabular}

(Almeida et al., 2013 )

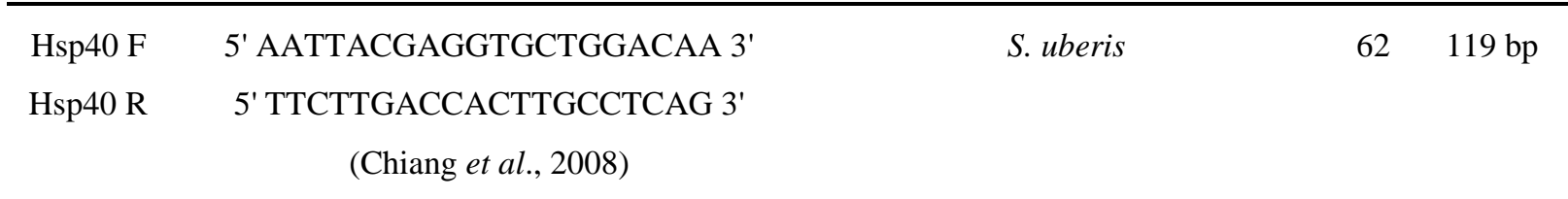

\begin{tabular}{lcccc}
\hline$c f u \mathrm{~F}$ & 5' $^{\prime}$ TATCCCGATTTGCAGCCTAC 3' & CAMP factor coding gene & 56 & $205 \mathrm{bp}$ \\
$c f u \mathrm{R}$ & 5' CCTGGTCAACTTGTGCAACTG 3' & &
\end{tabular}

(Reinoso et al., 2011)

\begin{tabular}{|c|c|c|c|c|}
\hline $\begin{array}{l}\operatorname{gap} C \mathrm{~F} \\
\operatorname{gap} C \mathrm{R}\end{array}$ & $\begin{array}{l}\text { 5' GCTCCTGGTGGAGATGATGT 3' } \\
\text { 5' GTCACCAGTGTAAGCGTGGA 3' } \\
\text { (Reinoso et al., 2011) }\end{array}$ & $\begin{array}{l}\text { Glyceraldehydes 3- phosphate } \\
\text { dehydrogenase protein gene } \\
\text { (GAPDH) }\end{array}$ & 56 & $200 \mathrm{bp}$ \\
\hline $\begin{array}{l}o p p F \mathrm{~F} \\
o p p F \mathrm{R}\end{array}$ & $\begin{array}{l}\text { 5' GGCCTAACCAAAACGAAACA 3' } \\
\text { 5' GGCTCTGGAATTGCTGAAAG 3' } \\
\text { (Smith et al., 2002) }\end{array}$ & Oligopeptide permease gene & 53 & $419 \mathrm{bp}$ \\
\hline $\begin{array}{l}l b p \mathrm{~F} \\
l b p \mathrm{R}\end{array}$ & $\begin{array}{l}\text { 5' CGACCCTTCAGATTGGACTC 3' } \\
\text { 5' TAGCAGCATCACGTTCTTCG 3' } \\
\text { (Reinoso et al., 2011) }\end{array}$ & Lactoferrin-binding proteins gene & 53 & $698 \mathrm{bp}$ \\
\hline $\begin{array}{l}\text { sau } \mathrm{F} \\
\text { sau } \mathrm{R}\end{array}$ & $\begin{array}{l}\text { 5' ACGCAAGGTGCTCAAGAGTT 3' } \\
\text { 5' TGAACAAGCGATTCGTCAAG 3' } \\
\text { (Reinoso et al., 2011) }\end{array}$ & $\begin{array}{l}\text { S.uberis specific adhesion molecule } \\
\text { gene }\end{array}$ & 63 & 776 bp \\
\hline
\end{tabular}




\section{Molecular confirmation of presumptive} Streptococcus isolates by PCR:

All presumptive isolates were subjected to Streptococcus general specific PCR assay using the primer pair (St F and St R) that was specific to all Streptococcus species. PCR was performed in $25 \mu 1$ reaction volumes containing $5 \mu \mathrm{l}$ of DNA template, 20 pmol of each primer and 1X of PCR master mix (Dream Taq Green PCR Master Mix, Fermentas Life Science). Amplification was carried out in a Nexus gradient Master cycler (Eppendorf, Germany) under the following conditions: one cycle of initial denaturing at $95^{\circ} \mathrm{C}$ for 5 min and 40 three-step cycles, which included denaturation at $94^{\circ} \mathrm{C}$ for $30 \mathrm{~s}$, annealing at $58^{\circ} \mathrm{C}$ for $30 \mathrm{~s}$, and extension at $72^{\circ} \mathrm{C}$ for $45 \mathrm{~s}$. PCR products were analyzed in $2 \%$ agarose gel stained with ethidium bromide. Amplification of 281 bp products confirmed the isolate to be Streptcoccus spp.

4. Molecular confirmation of $S$. uberis amongst PCR confirmed Streptococcus isolates:

All Streptococcus confirmed isolates were subjected to $S$. uberis specific PCR using Hsp40 F and Hsp40 R primer set using the above mentioned amplification condition except $62^{\circ} \mathrm{C}$ for annealing temperature. Amplification of $119 \mathrm{bp}$ confirmed the isolate to be S.uberis.
5. Detection of virulence genes amongst $S$. uberis confirmed isolates by PCR:

Five different virulence markers were assayed by different PCR assays. Amplification conditions used for these PCR assays were as previously mentioned but with the specified annealing temperatures shown in table 1.

\section{RESULTS}

From the total number of 240 milk samples under the current study, 74 Streptococcus spp. were isolated with a percentage of $30.8 \%$. PCR using Streptococcus specific primer set confirmed all the isolates to be Streptococcus species. Based on both biochemical tests and S. uberis specific PCR assay, 48 out of 74 Streptococcus isolates were confirmed to be $S$. uberis with a percentage of $64.9 \%$. Figure 1 (A \& B) showed the specific PCR products of both Streptococcus specific and $S$. uberis specific PCR assays. Table (2) showed the incidence of $S$. uberis isolated from different types of milk samples. It was found that, the overall percentage of $S$. uberis isolation in the examined milk samples was $20 \%$. Additionally, the higher incidence of $S$. uberis was found in bulk tank milk samples $(45.5 \%)$ followed by clinical and subclinical milk samples $(18.2 \%$ and $11.1 \%$, respectively).

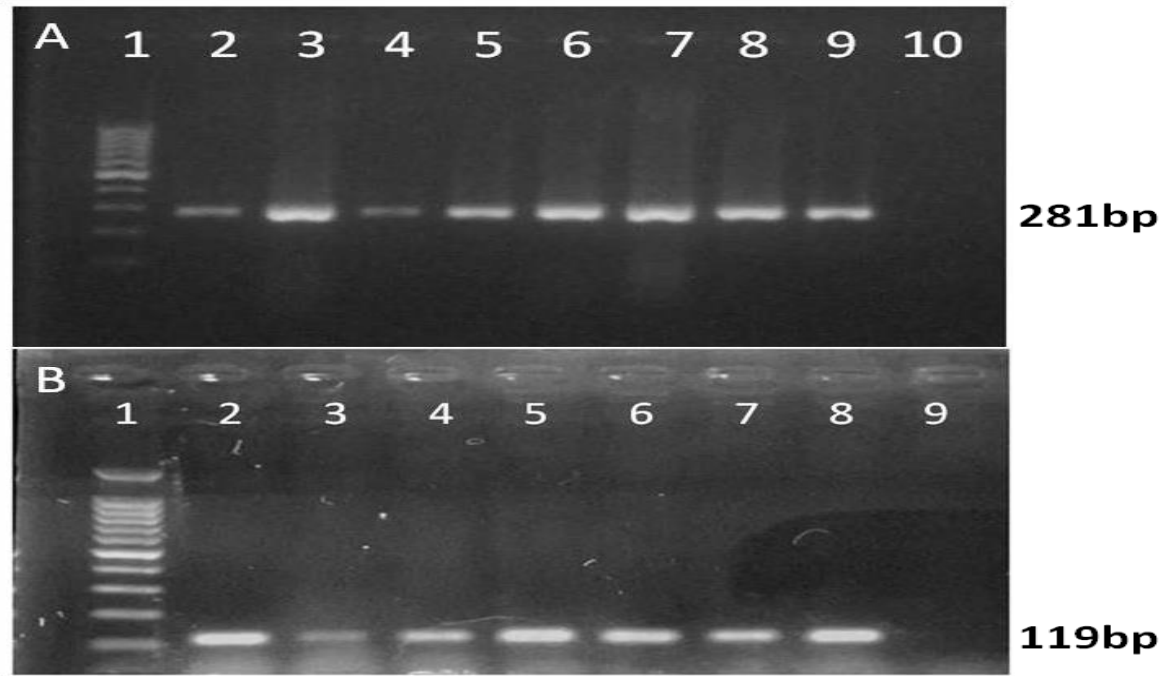

Figure 1: (A) Positive amplification of 281 bp PCR products of Streptococcus species specific PCR assay. Lane

1: 100 bp ladder DNA marker, lane 2-9: positive Streptococcus isolates and lane 10: negative control.

(B) Positive amplification of 119 bp PCR products of $S$. uberis specific PCR assay. Lane 1: 100 bp ladder DNA marker, lanes 2-8: positive S. uberis isolates, Lane 9: negative control.

Table 2: Incidence rate of $S$. uberis in different cow's milk samples.

\begin{tabular}{lccc}
\hline \multicolumn{1}{c}{ Cow's milk samples } & $\begin{array}{c}\text { No. of } \\
\text { milk samples }\end{array}$ & No & $\%$ \\
\hline Subclinical mastitic milk & 108 & 12 & $11.1 \%$ \\
\hline Clinical mastitic milk & 88 & 16 & $18.2 \%$ \\
\hline BTM & 44 & 20 & $45.5 \%$ \\
\hline Total & 240 & 48 & $20 \%$ \\
\hline
\end{tabular}


All confirmed $48 \mathrm{~S}$. uberis isolates were examined for their virulence using three different tests including haemolysis type, CAMP factor reaction and slime production status. Figures (2 and 3 ) showed the positive CAMP factor reaction and slime production on Congo red agar plates of $S$. uberis isolates, respectively. Table (3) showed the haemolysis types, CAMP factor reactions and slime production status of
$S$. uberis confirmed isolates. The results indicated high prevalence of $S$. uberis isolates with $\alpha$ haemolysis, negative CAMP factor reaction and slime production between $(87.5 \%, 93.75 \%$ and $75 \%$, respectively). On the other side, the percentages of $S$. uberis with $\beta$-haemolysis and positive CAMP factor reaction were $6.25 \%$ for each of them.

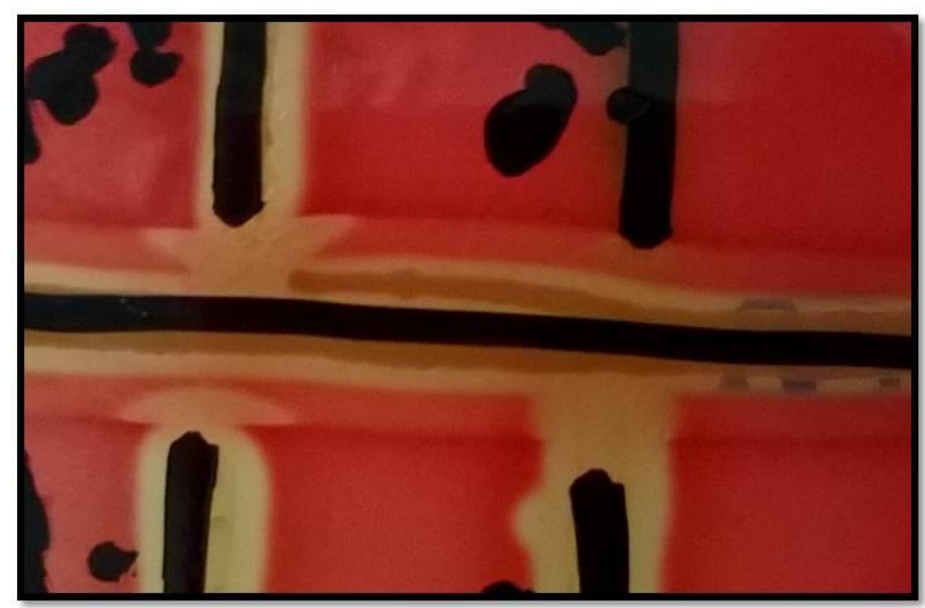

Figure 2: A synergistic haemolytic CAMP-factor like reaction of $S$. uberis isolates on sheep blood agar within the zone of $\beta$ - haemolytic $S$. aureus represented by the head of an arrow haemolysis.

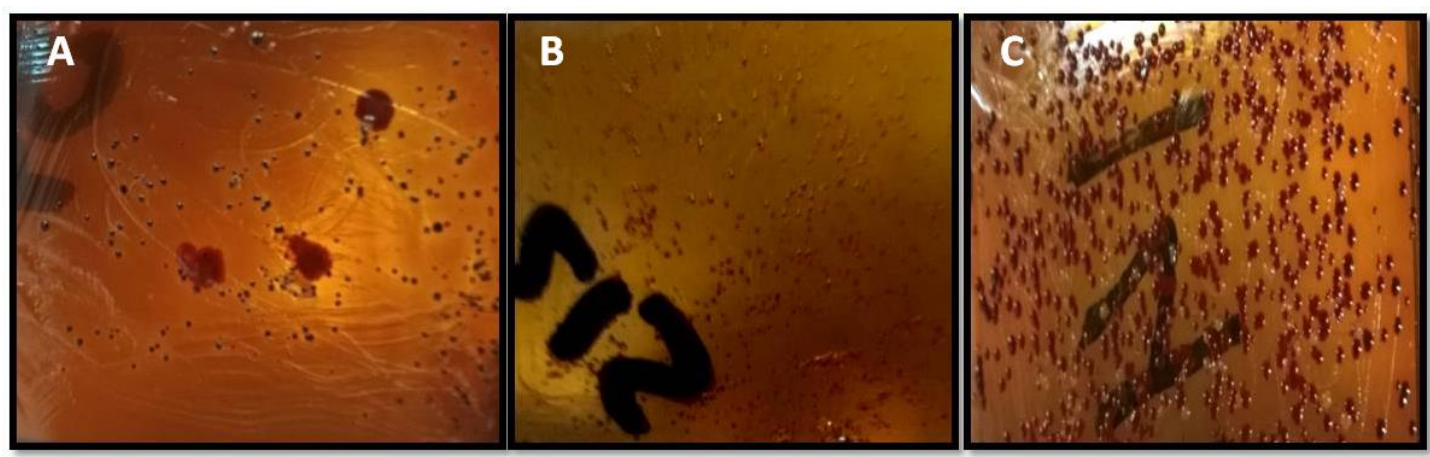

Figure 3: (A) Dry black crystalline strong biofilm producer S. uberis isolate. (B) Dry red intermediate biofilm producer $S$. uberis isolate. (C) Smooth red non biofilm producer S. uberis isolate.

Table 3: Prevalence of different haemolysis types, CAMP factor reaction and slime production status among $S$. uberis isolates.

\begin{tabular}{lccccccc}
\hline No. of & \multicolumn{3}{c}{ Haemolysis types } & \multicolumn{2}{c}{ CAMP factor reaction } & \multicolumn{2}{c}{ Slime production } \\
\cline { 2 - 7 } S. uberis & $\alpha$ & $\beta$ & $\Upsilon$ & Positive & Negative & Positive & Negative \\
& No. $(\%)$ & No. $(\%)$ & No. $(\%)$ & No. $(\%)$ & No. $(\%)$ & No. $(\%)$ & No. $(\%)$ \\
\hline 48 & 42 & 3 & 3 & 3 & 45 & 36 & 12 \\
& $(87.5 \%)$ & $(6.25 \%)$ & $(6.25 \%)$ & $(6.25 \%)$ & $(93.75 \%)$ & $(75 \%)$ & $(25 \%)$
\end{tabular}

All 48 S. uberis isolates were tested for their in vitro antimicrobial sensitivity using disk diffusion method. Table (4) showed the numbers and percentages of both sensitive and resistant $S$. uberis isolates for each type of antibiotics. Figure (4) showed both a highly sensitive and a highly resistant $S$. uberis isolates on Muller Hinton agar plates. The results cleared that the majority of the isolates were highly sensitive to FFC,
C, NOR and CIP $(89.6 \%, 77.1 \%, 70.8 \%$ and $66.7 \%$, respectively). More than half of S. uberis were susceptible to AMX and AMC (58.3\% and 56.3\%, respectively). On the other hand, most of the isolates (ranged between $77.1 \%$ and $95.8 \%$ of them) were highly resistant to E, S, TE, OX, P, AM, N and CX (Table 4). 


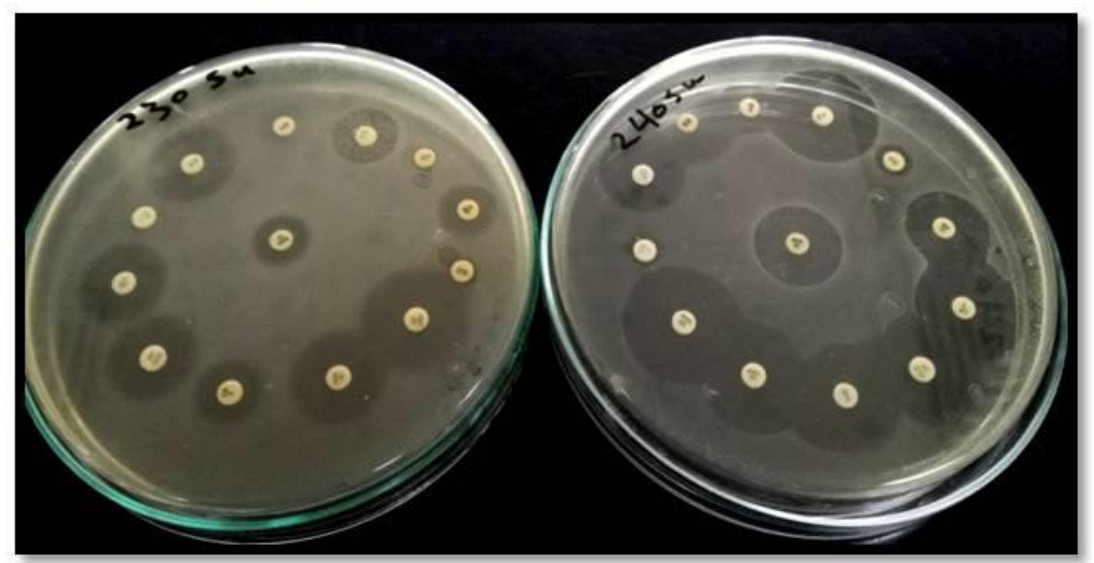

Figure 4: Highly resistant (left) and highly sensitive (right) S. uberis isolates to different antibiotics.

Table 4: Antimicrobial susceptibility patterns of S. uberis isolates.

\begin{tabular}{ccccc}
\hline \multirow{2}{*}{ Antibiotic disks } & \multicolumn{2}{c}{ Sensitive strains } & \multicolumn{2}{c}{ Resistant strains } \\
\cline { 2 - 4 } & No. & $\%$ & No. & $10.4 \%$ \\
\hline FFC & 43 & $89.6 \%$ & 5 & $22.9 \%$ \\
\hline C & 37 & $77.1 \%$ & 11 & $29.2 \%$ \\
\hline NOR & 34 & $70.8 \%$ & 14 & $33.3 \%$ \\
\hline CIP & 32 & $66.7 \%$ & 16 & $41.7 \%$ \\
\hline AMX & 28 & $58.3 \%$ & 20 & $43.7 \%$ \\
\hline AMC & 27 & $56.3 \%$ & 21 & $77.1 \%$ \\
\hline E & 11 & $22.9 \%$ & 37 & $83.3 \%$ \\
\hline S & 8 & $16.7 \%$ & 40 & $95.8 \%$ \\
\hline TE & 5 & $10.4 \%$ & 43 & $95.8 \%$ \\
\hline OX & 2 & $4.2 \%$ & 46 & $95.8 \%$ \\
\hline P & 2 & $4.2 \%$ & 46 & $95.8 \%$ \\
\hline AM & 2 & $4.2 \%$ & 46 & $95.8 \%$ \\
\hline N & 2 & $4.2 \%$ & 46 & 46 \\
\hline
\end{tabular}

All 48 S. uberis isolates were also screened for the presence of five virulence associated genes using different PCR assays. Figures 5 (A-D) showed the positive amplification products of different PCR assays used for detection of gapC, oppF, sau and $c f u$ genes, respectively.

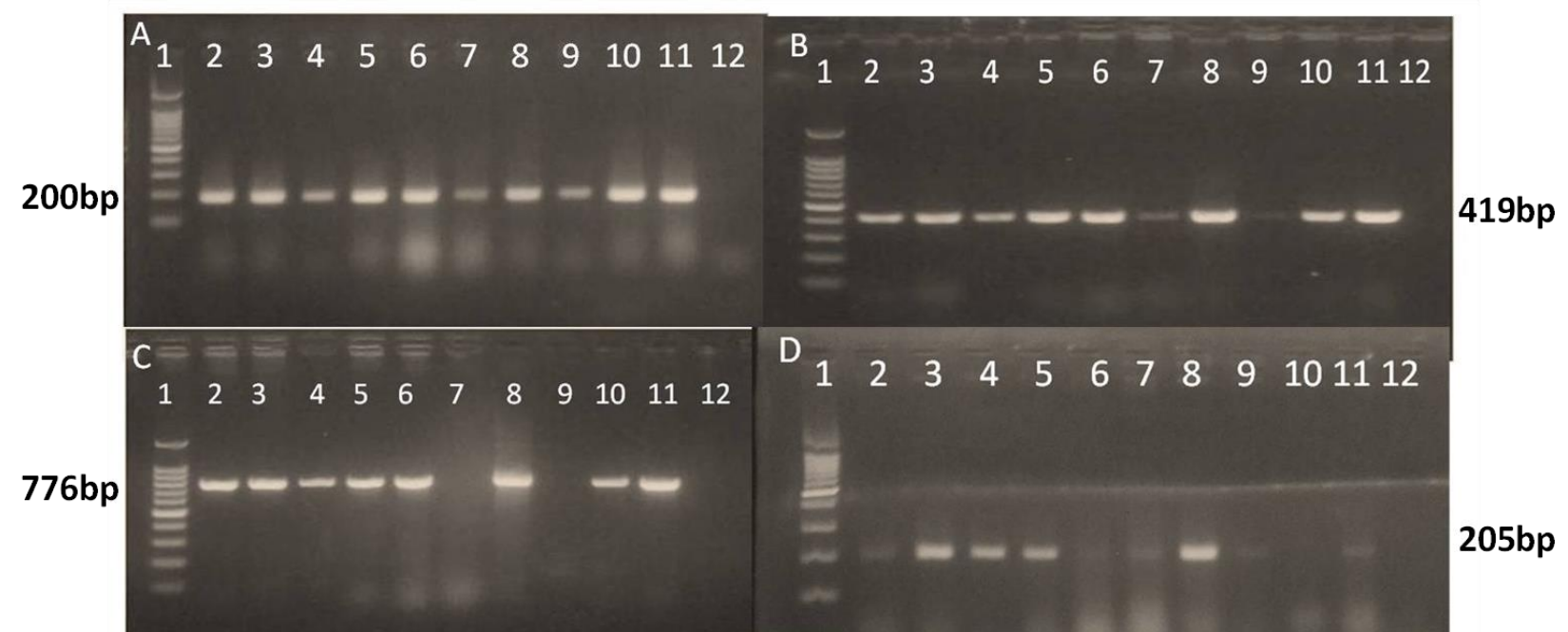

Figure 5: (A) Positive amplification of 200 bp PCR products of gapC gene. Lane 1: 100 bp ladder DNA marker, lanes 2-11: gapC positive $S$. uberis isolates and lane 12: negative control. (B) Positive amplification of 419 bp PCR products of oppF gene. Lane 1: 100 bp ladder DNA marker, lanes 2-11: oppF positive $S$. uberis isolates and lane 12: negative control. (C) Positive amplification of 776 bp PCR products of sau gene. Lane 1: 100 bp ladder DNA marker, lanes 2-6; 8; 10-11: sau gene positive $S$. uberis isolates; lanes 7\& 9: sau gene negative $S$. uberis isolates and lane 12: negative control. (D) Positive amplification of $205 \mathrm{bp}$ PCR products of $c f u$ gene. Lane 1: $100 \mathrm{bp}$ ladder DNA marker, lanes 2-9, 11: $c f u$ gene positive isolates and lane 10: $c f u$ gene negative isolate; Lane 12: negative control. 
Table (5) showed the number and percent of $S$. uberis isolates positive for each type of virulence genes. As shown in table 5, gapC gene was detected in all the isolated strains of $S$. uberis while oppF, cfu and sau genes were detected in percentages of $93.8 \%, 68.8 \%$ and $62.5 \%$, respectively. On the contrary, $l b p$ gene couldn't be detected in any of the isolated S. uberis. The prevalence of different virulence genes among $S$. uberis isolates from different types of milk samples was shown in table (6). It showed that $S$. uberis isolates contained at least two types of virulence genes while some isolates carried three or four virulence genes. The higher rate of $S$. uberis harboring 4 virulence genes was detected in that isolated from clinical mastitis. Moreover, the higher strains harboring 3 virulence genes were detected in that isolated from subclinical mastitis.

Table 5: Prevalence of different virulence gene types in S. uberis isolates.

\begin{tabular}{ccc}
\hline Types of virulence genes & \multicolumn{2}{c}{ Positive isolates } \\
\cline { 2 - 3 } & Number & $100 \%$ \\
\hline$g a p C$ & 48 & $93.8 \%$ \\
\hline$o p p F$ & 45 & $68.8 \%$ \\
\hline$c f u$ & 33 & $62.5 \%$ \\
\hline$s a u$ & 30 & 0 \\
\hline$l b p$ & Not detected & 6
\end{tabular}

Table 6: Prevalence of virulence genes among the $S$. uberis isolates from different milk samples.

\begin{tabular}{|c|c|c|c|c|}
\hline \multirow[t]{2}{*}{ Cow's milk samples } & \multirow{2}{*}{$\begin{array}{l}\text { No. of } \\
\text { isolates }\end{array}$} & \multicolumn{3}{|c|}{ No. of detected genes/no. of S. uberis isolates (\%) } \\
\hline & & 4 genes & 3 genes & 2 genes \\
\hline Subclinical mastitic milk & 12 & 0 & $8(66.7 \%)$ & $4(33.3 \%)$ \\
\hline Clinical mastitic milk & 16 & $9(56.25 \%)$ & $3(18.75 \%)$ & $4(25 \%)$ \\
\hline BTM & 20 & $8(40 \%)$ & $9(45 \%)$ & $3(15 \%)$ \\
\hline Total & 48 & $17(35.4 \%)$ & $20(41.7 \%)$ & $11(22.9 \%)$ \\
\hline
\end{tabular}

\section{DISCUSSION}

Streptococcus uberis is a worldwide pathogen that causes intra-mammary infections in dairy cattle. $S$. uberis has been described as an opportunistic pathogen that utilizes nutritional flexibility to adapt to a range of ecological niches, including the mammary gland (Ward et al., 2009 and Collado et al., 2016). It was suggested that cow-to-cow transmission of $S$. uberis potentially occurring in the majority of herds and may be the most important route of infection in many herds (Davies et al., 2016).

In this study, a total number of 240 different milk samples were collected from clinical, subclinical and bulk tank milk samples of different dairy cow farms aiming to isolate $S$. uberis that cause bovine mastitis to study its phenotypic and genotypic characteristics. Based on both phenotypic and genotypic identification, the number of Streptococcus spp. isolated from all tested milk samples was 74 (30.8\%). Also, the confirmed S. uberis strains were 48 out of 74 Streptococcus spp. (64.9\%). Previously, lower and higher percentages of $S$. uberis detection in mastitic milk samples, ranged from $39.9 \%, 55.38 \%, 55.38 \%$ and $18.48 \%$ of the isolated Streptococcal spp. were reported by Rossitto et al. (2002); Amosun et al. (2010); Adesola (2012) and Kia et al. (2014), respectively.

In contrast to the total examined milk samples, the incidence of S. uberis was 20\%. Nearly similar, Ebrahimi et al. (2008) isolated S. uberis from normal, sub-acute and acute cow mastitic cases with a percentage of $18 \%$. A higher incidence rate of Streptococcus spp. were isolated from mastitic cows $(55 \%)$ but a lower $S$. uberis was isolated with a percentage of $15.3 \%$ was detected by El-Jakee et al. (2013). Also, a higher incidence of $S$. uberis as the predominant pathogen was recorded by Steele et al. (2015) in cow's milk samples $(46 \%)$. This variation in the results might be attributed to the difference in herd management between herds. Some practices can decrease the incidence as teat dipping before and after milking, washing milkers hands before and after milking, preparation of clean towel for each lactating cow, milking of infected cow lastly, using dry cow therapy method and treating clinical cases at early stage (Teklemariam et al., 2015). 
In the current study, the higher $S$. uberis incidence rate was detected in bulk tank milk samples (45.5\%). A higher incidence rate was detected by Zadoks et al. (2004) who cultured BTM samples from 48 dairy herds and found $81 \%$ positive for $S$. uberis. Very high incidence was reported by Katholm et al. (2012) who found S. uberis in $95 \%$ of BTM. Otherwise, Bi et al. (2016) isolated S. uberis in only $8.9 \%$ of BTM. Dogan and Boor (2004) suggested that high numbers of $S$. uberis in BTM were more likely to reflect high numbers of $S$. uberis shed by mastitic cows, rather than multiplication of these organisms under cooling conditions required for production of Grade A milk.

In clinical and subclinical mastitic milk samples, $S$. uberis was detected in $18.2 \%$ and $11.1 \%$, respectively. Higher incidence of $S$. uberis was recovered from milk of clinical mastitic cows with $26.3 \%$, while in subclinical mastitic milk samples, $S$. uberis was detected in $16.7 \%$ (El-Jakee et al., 2013). In contrary, Teklemariam et al. (2015) found that, the prevalence of $S$. uberis isolation in subclinical mastitis was higher than that of clinical mastitis (88.9 $\%$ and $11.1 \%$, respectively).

The differences in the incidence rates of $S$. uberis clinical and subclinical mastitis in the previous researches was explained by Günther et al. (2016) who demonstrated that all $S$. uberis isolates from clinical and subclinical mastitis evaded the immune surveillance of the mammary epithelial cells (MEC), representing by far the most abundant first line sentinels of the udder. Failure to activating their immune alert early after infection explained the commonly observed belated and weak onset of udder inflammation during $S$. uberis mastitis. On the other hand they proved that macrophages can indeed mount a vigorous immune response against $S$. uberis.

In this work we studied some of phenotypic characteristics of the isolated strains of $S$. uberis that indicated to virulence factors. The $1^{\text {st }}$ step on detecting phenotypic virulence factors of $S$. uberis isolates was their haemolytic effect on sheep blood agar. The higher percentage of $S$. uberis isolates showed $\alpha$ haemolysis $(87.5 \%)$, while $\beta$ or $\Upsilon$ haemolysis was recorded in only $6.25 \%$ (for each of them) of the isolates. In this side of work, Kia et al. (2014) reported that all $S$. uberis in their study were $\alpha$ haemolysic strains.

The role of CAMP factor in pathogenicity is unclear, although it can't be ruled out as a putative virulence factor (Lasagno et al., 2011). Considering CAMP factor like reaction only $6.25 \%$ of the tested $S$. uberis isolates were positive for CAMP factor reaction in our study. While, Christ et al. (1988); Lämmler (1991); Khan et al. (2003) and Lasagno et al. (2011) found $10 \%, 25 \%, 3.9 \%$ and $28 \%$ CAMP positive $S$. uberis strains, respectively.
Biofilms provide a sheltered and protected area for bacterial growth allowing them to be resistant to antibiotics; disinfectants and host defenses, thus the difficulties of treating recurrent infections may be related to the ability of the infecting pathogens to produce biofilms (Melchior et al, 2005). Therefore, the ability of $S$. uberis to produce slime might be a desirable virulence factor during colonization of the udder. It has been shown that slime production is important; allowing the bacteria to aggregate and form biofilms (Arciola et al., 2002).

Slime production indicating biofilm formation was detected in $75 \% \mathrm{~S}$. uberis isolates in this study. Moore (2009) detected strong S. uberis biofilm former in $78 \%$ of the tested strains isolated from mastitic cows and when evaluated for slime (polysaccharide) production, all 27 strains were positive by the Congo red agar method. Recently, Collado et al. (2016) reported that different $S$. uberis strains have the ability to form biofilm in vitro. The high incidence of biofilm formation among the isolated strains may be due to that milk or its components could contribute to the pathogenesis of $S$. uberis mastitis by assisting in biofilm production as the indigenous flora of raw milk appears to contribute to biofilm formation by $S$. uberis since limited amounts of biofilm were produced when indigenous flora were removed from milk (Almeida et al., 2015a).

Recent increase in antibiotics resistance of bacterial strains isolated from cow milk with mastitis represented a strong motivation to study the most efficient antibiotic for treatment (Nadăş et al., 2014). In studying the antimicrobial susceptibility of the isolated $S$. uberis strains, it was noticed that they were highly susceptible to FFC and C. Guérin-Faublée et al. (2002) and Moges et al. (2011) recorded that all $S$. uberis strains isolated from mastitic milk were susceptible to $\mathrm{C}$. On the other hand most of the isolates (ranged between $77.1 \%$ and $95.8 \%$ of them) were highly resistant to $\mathrm{E}, \mathrm{S}, \mathrm{TE}, \mathrm{OX}, \mathrm{P}, \mathrm{AM}, \mathrm{N}$ and CX. In accordance with our results, Ebrahimi et al. (2008) also observed a high resistance rate among $S$. uberis isolates against $\mathrm{S}, \mathrm{P}, \mathrm{AM}$ and $\mathrm{CX}$. According to Piepers et al. (2007) S. uberis was more frequently resistant to the penicillin within the class of penicillins. Adesola (2012) illustrated that, all their studied $S$. uberis isolates were resistant to AM, N and TE. Recently, Petrovski et al. (2015) reported that all streptococcal isolates demonstrated resistance to aminoglycosides (N and $\mathrm{S}$ ). Discordant isolates of $S$. uberis that were susceptible to penicillin, but resistant to $\mathrm{OX}$, were also found demonstrated cross-resistance to the cephalosporins tested. So they recommended that the treatment of bovine mastitis caused by Streptococci, particularly S. uberis, with isoxazolyl penicillins should be discouraged nationally and internationally. 
S. uberis is an important pathogen that has been implicated in bovine mastitis but the virulence factors associated with pathogenesis are not well understood (Reinoso et al. 2011). Our study aimed to detect 5 putative and known virulence-associated genes by PCR assays in $48 \mathrm{~S}$. uberis strains isolated from different cow's milk samples of different dairy farms. The results revealed that gapC gene was detected in all the isolated strains of $S$. uberis. While oppF, $c f u$ and sau genes were detected in $93.8 \%, 68.8 \%$ and $62.5 \%$, respectively. On the contrary, $l b p$ gene couldn't be detected in any of the isolated strains of $S$. uberis.

GapC was included because in several pathogenic bacteria GAPDH protein has been described as being associated with virulence (Maeda et al., 2004) due to its ability to bind several host proteins (Pancholi and Fischetti, 1993) or to confer resistance against reactive oxygen species produced by host phagocytic cells (Holzmuller et al., 2006).

Our result was higher than that recorded by Reinoso et al. (2011) who found gapC only in 62 (79.4\%) of $S$. uberis isolated from bovine mastitis. But in another recent work of Reinoso et al. (2015) they recorded the presence of sua, $c f u$, and gapC genes in the most of $S$. uberis strains.

Another gene included in this study was $o p p F$, which is another important factor playing a significant role during growth of $S$. uberis in milk. The essential amino acids can be taken up by $S$. uberis through the expressed oligopeptide binding protein encoded by the oppF gene (Smith et al., 2002 and Taylor et al., 2003). The oppF gene was successfully detected in $93.8 \%$ of $S$. uberis isolates. On the contrary, it was reported to be absent by Zadoks et al. (2005) while Reinoso et al. (2011) found it in $64.1 \%$ of the strains.

The gene $c f u$, coding for CAMP factor in S. uberis, is a further putative virulence factor homologous to $\mathrm{Fc}$ binding (Reinoso et al., 2011). cfu gene was detected in $68.8 \%$ in this study, however, a positive CAMP reaction was observed only in $6.25 \%$ using phenotypic method. This difference was also supported by (Reinoso et al., 2011) who found $c f u$ gene in $76.9 \%$ of the strains examined although a positive CAMP reaction was observed in only $23 \%$ of S. uberis strains. Our result was in contrast to those of Khan et al. (2003), who reported positive cfu gene in $3.8 \%$ of $S$. uberis strains corresponding to a phenotypically positive CAMP-reaction only. These conflicted results suggested that the presence of this gene might not be related to expression of the CAMP factor (Reinoso et al., 2011). This may explain the difference observed here and by Khan et al. (2003). On the other hand, Ward et al. (2009) showed that a coding sequence for CAMP factor was not identified in S. uberis 0140J that is pathogenic for both the lactating and non-lactating bovine mammary gland.
Adherence to and internalization into MEC are central mechanisms in the pathogenesis of S. uberis mastitis. The ability to adhere to and invade into bovine mammary epithelial cells (BMEC) was potentially mediated by the $S$. uberis adhesion molecule (SUAM). Through these pathogenic strategies, $S$. uberis reaches an intracellular environment where humoral host defenses and antimicrobials in milk are essentially ineffective, thus allowing persistence of this pathogen in the mammary gland (Prado et al., 2011 and Almeida et al., 2015b). In our study the presence of sua gene was declared in $62.5 \%$ of the tested S. uberis isolates however many previous works reported higher prevalence of the sua gene. Reinoso et al. (2011) reported a prevalence of the sua gene of $83.3 \%$ in their study. Shome et al. (2012) and Yuan et al. (2014) detected sua gene in $100 \%$ of the examined S. uberis strains. Recenty, Perrig et al. (2015) illustrated that the prevalence of the sua was $97.8 \%$ of 137 S. uberis isolates from bovine milk with subclinical or clinical mastitis. Our lower prevalence of sua gene in the tested S. uberis isolates may be attributed to an intact sua gene does not appear necessary for adherence (Tassi et al., 2015).

In the current work, $l b p$ can't be detected in any isolate of $S$. uberis under the study, while Reinoso et al. (2011) found $l b p$ in $11.5 \%$ and this was a very low prevalence when compared with other genes they detected. This may be attributed to that the presence of $l b p$ gene isn't necessary for virulence of $S$. uberis. As Almeida et al. (2015b) reported that S. uberis expresses SUAM that has affinity for lactoferrin (Lf) and a central role adherence to and internalization of S. uberis into BMEC. Mechanisms underlying the pathogenic involvement of SUAM rely partially on its affinity for Lf, which together with a putative receptor on the surface of BMEC creates a molecular bridge which facilitates adherence to and internalization of $S$. uberis into MEC (Almeida et al., 2006 and Patel et al., 2009). Since adhesion is the first step in biofilm formation, it is possible that $\mathrm{Lf}$ contributes to that process.

Finally, we noticed that at least 2 of the five different virulence genes were detected in each isolate of $S$. uberis under the study. There were some strains harboring 4 virulence genes the higher level of these strains was detected in that isolated from clinical mastitis (56. 25\%). Moreover the higher strains harboring 3 virulence genes were detected in that isolated from subclinical mastitis $(66.7 \%)$. Notcovich et al. (2016) reported that, there were significant differences between the strains in the proportion of quarters developing clinical mastitis. These results illustrated the difference in the ability of S. uberis strains to cause mastitis and the severity of the infections caused. In agreement with the present results, Reinoso et al. (2011) found that not all genes were present in the strains but all of the detected virulence-associated genes were present in 
combination. Also, they found $60.3 \%$ isolates carried seven to 10 virulence-associated genes and detection of virulence-associated genes in individual S. uberis strains isolated from infected animals revealed one to 10 virulence genes. Reinoso et al. (2015) recorded the presence of 3 genes in most of $S$. uberis strains.

\section{CONCLUSION}

S. uberis should be given a great concern as a threat for the dairy cows. It was isolated from milk of both clinincal and subclinical mastitis as well as it was isolated with high percentage in BTM. So, S. uberis is becoming a major health problem of dairy cows and undoubtedly will have an adverse effect on productivity of dairy industry. Moreover, this pathogen nowadays emerges as resistance to different antimicrobial agents especially for those commonly utilized. Furthermore, S. uberis harbors different virulence factors and genes that allow it to persist in the mammary gland of the dairy animals for a long time and speeding of infection from cow to cow may occur resulting in higher prevalence rates of infection between different dairy farms.

\section{REFRENCES}

Adesola, A.E. (2012): Antimicrobial resistance pattern of Streptococci and Staphylococci isolated from cases of bovine clinical mastitis in Nigeria. Nat. Sci., 10 (11): 96-101.

Almeida, A.; Albuquerque, P.; Araujo, R.; Ribeiro, N. and Tavares, F. (2013): Detection and discrimination of common bovine mastitis causing Streptococci. Vet. Microbiol., 164: 370-377.

Almeida, R.A.; Kerro-Dego, O.; Prado, M.E.; Headrick, S.I.; Lewis, M.J.; Siebert, L.J.; Pighetti, G.M. and Oliver, S.P. (2015a): Protective effect of anti-SUAM antibodies on Streptococcus uberis mastitis. Vet. Res., 46:133.

Almeida, R.A.; Kerro-Dego, O.; Headrick, S.I.; Lewis, M.J. and Oliver, S.P. (2015b): Role of Streptococcus uberis adhesion molecule in the pathogenesis of Streptococcus uberis mastitis. Vet. Microbiol., 30;179 (3-4): 332-335.

Almeida, R.A.; Luther, D.A.; Park, H.M. and Oliver, S.P. (2006): Identification, isolation, and partial characterization of a novel Streptococcus uberis adhesion molecule (SUAM). Vet. Microbiol., 115:183-191.

Amosun, E.A.; Ajuwape, A.T.P. and Adetosoye, A.I. (2010): Bovine Streptococcal mastitis in Southwest and Northern States of Nigeria. Afr. J. Biomed. Res., 13(1): 33-37.

Arciola, C.R.; Campoccia, D. and Montanaro, L. (2002): Detection of biofilm-forming strains of Staphylococcus epidermidis and S. aureus. Expert Rev. Mol. Diag., 2(5):478-484.
Asfour A.E. Hanaa and Darwish F. Samah (2011): Phenotypic and genotypic detection of both $m e c A-$ and blaZ genes mediated $\beta$-lactam resistance in Staphylococcus strains isolated from bovine mastitis. Global Veterinaria. 6 (1): 39-50.

Bi, Y.; Wang, Y.J.; Qin, Y.; Guix Vallverdú, R.; Maldonado García, J. and Sun, W. (2016): Prevalence of bovine mastitis pathogens in bulk tank milk in China. PLoS ONE. 11(5): 13 pages.

Chiang, YC.; Pai, WY.; Chen, C.Y. and Tsen, HY. (2008): Use of primers based on the heat shock protein genes hsp 70, hsp 40, and hsp 10, for the detection of bovine mastitis pathogens Streptococcus agalactiae, Streptococcus uberis and Streptococcus bovis. Molecular and Cellula probes. 22: 262-266.

Christ, D.; Schwarz, S. and Lämmler, C. (1988): DNA finger printing of Streptococcus uberis. Med. Sci. Res., 16: 1297-1298.

Collado, R.; $\quad$ Prenafeta, A.; González-González, L.; Pérez-Pons, J.A. and Sitjà, M. (2016): Probing vaccine antigens against bovine mastitis caused by Streptococcus uberis. Vaccine. 34(33): 3848-3854.

Davies, P.L.; Leigh, J.A.; Bradley, A.J.; Archer, S.C.; Emes, R.D. and Green, M.J. (2016): Molecular epidemiology of Streptococcus uberis clinical mastitis in dairy herds: Strain heterogeneity and transmission. J. Clin. Microbiol., 54 (1): 68-74.

Dogan, B. and Boor, K.J. (2004): Short communication: growth characteristics of Streptococcus uberis in UHT-treated milk. J. Dairy Sci., 87(4):813-815.

Ebrahimi, A.; Nikookhah, F.; Nikpour, S.; Majiian, F. and Gholami, M. (2008): Isolation of Streptococci from milk samples of normal, acute and subclinical mastitis cows and determination of their antibiotic susceptibility patterns. Pak. J. Biol. Sci., 11(1):148-50.

El-Jakee, J.; Hableel, H.S.; Kandil, M.; Hassan, O.F.; Khairy, E.A. and Marouf, S.A. (2013): Antibiotic resistance patterns of Streptococcus agalactiae isolated from mastitic cows and ewes in Egypt. Global Veterinaria 10 (3): 264-270.

Guérin-Faublée, V.; Tardy, F.; Bouveron, C. and Carret, G. (2002): Antimicrobial susceptibility of Streptococcus species isolated from clinical mastitis in dairy cows. Int. J. Antimicrob. Agents. 19(3): 219-226.

Günther, J.; Czabanska, A.; Bauer, I.; Leigh, J.A.; Holst, O. and Seyfert, H.M. (2016): Streptococcus uberis strains isolated from the bovine mammary gland evade immune recognition by mammary epithelial cells, but not of macrophages. Vet. Res., 47:13.

Holzmuller, P.M.; Hide, D.; Sereno, D. and Lemesre, J.L. (2006): Leishmania infantum amastigotes resistant to nitric oxide cytotoxicity: impact on 
in vitro parasite developmental cycle and metabolic enzyme activities. Infect. Genet. Evol., 6: 187-197.

Jiang, M.; Babiuk, L. and Potter, A. (1996): Cloning, sequencing and expression of the CAMP factor gene of Streptococcus uberis. Microbiol. Path., 20: 297-307.

Katholm, J.; Bennedsgaard, T.W.; Koskinen, M.T. and Rattenborg, E. (2012): Quality of bulk tank milk samples from Danish dairy herds based on real-time polymerase chain reaction identification of mastitis pathogens. J. Dairy Sci., 95(10):5702-5708.

Khan, I.U.; Hassan, A.A.; Abdulmawjood, A.; Lämmler, C.; Wolter, W. and Zschöck, M. (2003): Identification and epidemiological characterization of Streptococcus uberis isolated from bovine mastitis using conventional and molecular methods. J. Vet. Sci., 4(3): 213-223.

Kia, G.; Mehdi, G. and Keyvan, R. (2014): Prevalence and antibiotic susceptibility of Streptococcus spp. in cows with mastitis in Germi, Iran. Anim. Vet. Sci., 2 (2): 31-35.

Kromker, V.; Reinecke, F.; Paduch, J.H. and Grabowski, N. (2014): Bovine Streptococcus uberis intramammary infections and mastitis. Clin. Microbial., 3,4: 1-7.

Lämmler, C. (1991): Biochemical and serological properties of Streptococcus uberis. J. Vet. Med., 38:737-742.

Lasagno, M.C.; Reinoso, E.B.; Dieser, S.A.; Calvinho, L.F.; Buzzola, F.; Vissio, C.; Bogni, C. and Odierno, L.M. (2011): Phenotypic and genotypic characterization of Streptococcus uberis isolated from bovine subclinical mastitis in Argentinean dairy farms. Rev. Argent. Microbiol., 43: 212-217.

Maeda, K.; Nagata, H.; Kuboniwa, M.; Kataoka, K.; Nishida, N.; Tanaka, M. and Shizukuishi, S. (2004): Characterization of binding of Streptococcus oralis glyceraldehyde-3 phosphate dehydrogenase to Porphyromonas gingivalis major fimbriae. Infect. Immun., 72: 5475-5477.

Mathur, T.; Singhal, S.; Khan, S.; Upadhyay, D.J.; Fatma, T. and Rattan, A. (2006): Detection of biofilm formation among the clinical isolates of Staphylococci: and evaluation of three different screening methods. Ind. J. Med. Microbiol., 24: 25-29.

Melchior, M.B.; Vaarkamp, H. and Fink-Gremmels, $J$. (2005): Biofilms: A role in recurrent mastitis infections. Vet. J., 171: 398-407.

Moges, N.; Asfaw, Y.; Belihu, K. and Tadesse, A. (2011): Antimicrobial susceptibility of mastitis pathogens from small holder dairy herds in and around Gondar, Ethiopia. J. anim. Vet. Adv., 10 (12): 1616-1622.

Moore, G.E. (2009): Biofilm production by Streptococcus uberis associated with intramammary infections. University of
Tennessee Honors Thesis Projects. Trace: Tennessee Research and Creative Exchange.

Moshynskyy, I.; Jiang, M.; Fontaine, M.; PerezCasal, J.; Babiuk, L. and Potter, A. (2003): Characterization of a bovine lactoferrin binding protein of Streptococcus uberis. Microb. Pathogenesis. 35: 203-215.

Nadăş, G.C.; Fiţ, N.; Bouari, C.; Chirilă, F.; Răpuntean, S. and Rus, V. (2014): The susceptibility to antibiotics of some bacterial strains isolated from cow milk with mastitis. Bull. UASVM Vet. Med., 71(2): 495-497.

National Committee for Clinical Laboratory Standards (NCCLS) (2008): Performance Standards for Antimicrobial Disk and Dilution Susceptibility Tests for Bacteria Isolated from Animals; Approved Standard, 2nd Edn. NCCLS Document M31- A3.Wayne, PA: National Committee for Clinical Laboratory Standards.

Notcovich, S.; deNicolo, G.; Williamson, N.B.; Grinberg, A.; Lopez-Villalobos, N. and Petrovski, K.R. (2016): The ability of four strains of Streptococcus uberis to induce clinical mastitis after intramammary inoculation in lactating cows. N. Z. Vet. J., 64(4):218-223.

Oliver, S.; Almeida, R. and Calvinho, L. (1998): Virulence factors of Streptococcus uberis isolated from cows with mastitis. Zbl. Vet. Med. B., 45: 461-471.

Pancholi, V. and Fischetti, V.A. (1993): Glyceraldehyde-3-phosphate dehydrogenase on the surface of group A Streptococci is also an ADP-ribosylating enzyme. P. Natl. Acad. Sci., 90: 8154-8158.

Patel, D.; Almeida, R.A.; Dunlap, J.R and Oliver, S.P. (2009): Bovine lactoferrin serves as a molecular bridge for internalization of Streptococcus uberis into bovine mammary epithelial cells. Vet. Microbiol., 137:297-301.

Pecka-Kiełb, E.; Vasil, M.; Zachwieja, A. Zawadzki, W. Elečko, J.; Zigo, F.; Illek, J. and Farkasǒvá, Z. (2016): An effect of mammary gland infection caused by Streptococcus uberis on composition and physicochemical changes of cows' milk. Pol. J. Vet. Sci., 19(1): 49-55.

Perrig, M.S.; Ambroggio, M.B.; Buzzola, F.R.; Marcipar, I.S.; Calvinhod, L.F.; Veaute, C.M. and Barbagelata, M.S. (2015): Genotyping and study of the pauA and sua genes of Streptococcus uberis isolates from bovine mastitis. Melina S. Rev. Argent. Microbiol., 47(4):282-294.

Petrovski, K.R.; Grinberg, A.; Williamson, N.B.; Abdalla, M.E.; Lopez-Villalobos, N.; Parkinson, T.J.; Tucker, I.G. and Rapnicki, P. (2015): Susceptibility to antimicrobials of mastitis-causing Staphylococcus aureus, Streptococcus uberis and Streptococcus dysgalactiae from New Zealand and the USA 
as assessed by the disk diffusion test. Aust. Vet. J., 93(7): 227-233.

Piepers, S.; De Meulemeester, L.; de Kruif, A.; Opsomer, G.; Barkema, H.W. and De Vliegher, $S$. (2007): Prevalence and distribution of mastitis pathogens in subclinically infected dairy cows in Flanders, Belgium. Dairy Res. J., 74: 478-483.

Prado, M,E.; Almeida, R.A.; Ozen, C.; Luther, D.A.; Lewis, M.J.; Headrick, S.J. and Oliver, S.P. (2011): Vaccination of dairy cows with recombinant Streptococcus uberis adhesion molecule induces antibodies that reduce adherence to and internalization of $S$. uberis into bovine mammary epithelial cells. Vet. Immunol. Immunopathol., 141:201-208.

Quinn, P.J.; Markey, B.K.; Leonard, F.C.; FitzPatrick, E.S.; Fanning, S. and Hartigan, P.J. (2011): Veterinary Microbiology and Microbial Disease. $2^{\text {nd }}$ ed., Wiley-Blackwell, J Wiley and Sons Ltd Publication, UK.

Reinoso, E.B.; Lasagno, M.C.; Dieser, S.A. and Odierno, L.M. (2011): Distribution of virulence-associated genes in Streptococcus uberis isolated from bovine mastitis. FEMS Microbiol. Lett., 318: 183-188.

Reinoso, E.B.; Lasagno, M.C. and Odierno, L.M. (2015): Genetic patterns of Streptococcus uberis isolated from bovine mastitis. Rev. Argent. Microbiol., 47(2):108-111.

Rossitto, P.V.; Ruiz, L.; Kikuchi, Y.; Glenn, K.; Luiz, K.; Watts, J.L. and Cullor, J.S. (2002): Antibiotic susceptibility patterns for environmental streptococci isolated from bovine mastitis in Central California Dairies, J. Dairy Sci., 85 (1): 132-138.

Shome, B.R.; Bhuvana, M.; Mitra, S.D.; Krithiga, N.; Shome, R.; Velu, D.; Banerjee, A.; Barbuddhe, S.B.; Prabhudas, K. and Rahman, H. (2012): Molecular characterization of Streptococcus agalactiae and Streptococcus uberis isolates from bovine milk. Trop. Anim. Health Prod., 44: 1981-92.

Smith, A.J.; Kitt, A.J.; Ward, P.N. and Leigh, J.A. (2002): Isolation and characterization of a mutant strain of Streptococcus uberis, which fails to utilize a plasmin derived beta-casein peptide for the acquisition of methionine. J. Appl. Microbiol., 93: 631- 639.

Steele, N.M.; Williamson, J.H.; Laven, R.A. and Hillerton, J.E. (2015): Using polymerase chain reaction to identify Streptococcus uberis in bovine milk: how does it compare with bacterial culture? Proceedings of the New Zealand Society of Animal Production. 75:2023.
Taponen, S. and Pyorala, S. (2006): Coagulase negative staphylococci as cause of bovine mastitis-Not so different from Staphylococcus aureus? Vet. Microbiol., 134: 29-36.

Tassi, R.; McNeilly, T.N.; Sipka, A. and Zadoks, R.N. (2015): Correlation of hypothetical virulence traits of two Streptococcus uberis strains with the clinical manifestation of bovine mastitis. Vet Res., 46:123.

Taylor, D.L.; Ward, P.N.; Rapier, C.D.; Leigh, J.A. and Bowler, L.D. (2003): Identification of a differentially expressed oligopeptide binding protein (OppA2) in Streptococcus uberis by representational difference analysis of cDNA. J. Bacteriol., 185:5210-5219.

Teklemariam, A.D.; Nigussie, H.; Tassew, A.; Tesfaye, B.; Feleke, A. and Sisay, T. (2015): Isolation and phenotypic characterization of Streptococcus uberis from mastitic cows in and around Batu town, Ethiopia. J. Animal \&Plant Sci., 26 (3): 4124-4137.

Varhimo, E.; Varmanen, P.; Fallarero, A.; Skogman, M.; Pyorala, S.; Livanainen, A.; Sukura, A.; Vuorela, P. and Savijoki, K. (2011): Alphaand beta-casein components of host milk induce biofilm formation in the mastitis bacterium Streptococcus uberis. Vet. Microbiol., 149: 381-389.

Ward, P.N.; Holden, M.T.; Leigh, J.A.; Lennard, N.; Bignell, A.; Barron, A.; Clark, L.; Quail, M.A.; Woodward, J.; Barrell, B.G.; Egan, S.A.; Fiel, T.R.; Maskell, D.; Kehoe, M.; Dowson, C.G.; Chanter, N.; Whatmore, A.M.; Bentley, S.D. and Parkhill, J. (2009): Evidence for niche adaptation in the genome of the bovine pathogen Streptococcus uberis. BMC Genomics. 28: 10-54.

Yuan, Y.; Dego, O.K.; Chen, X.; Abadin, E.; Chan, S.; Jory, L.; Kovacevic, S.; Almeida, R.A. and Oliver, S.P. (2014): Conservation of Streptococcus uberis adhesion molecule and the sua gene in strains of Streptococcus uberis isolated from geographically diverse areas. J. Dairy Sci., 97: 7668-7673.

Zadoks, R.N.; González, R.N.; Boor, K.J. and Schukken, Y.H. (2004): Mastitis-causing Streptococci are important contributors to bacterial counts in raw bulk tank milk. J. Food Prot., 67(12): 2644-2650.

Zadoks, R.N.; Schukken, H.Y. and Wiedmann, M. (2005): Multilocus sequence typing of Streptococcus uberis provides sensitive and epidemiologically relevant subtype information and reveals positive selection in the virulence gene pauA. J. Clin. Microbiol., 43: 2407-2417. 
التوصيف المظهرى والجينى للمكور السبحى يوبرس المعزول من لبن الأبقار المصابة بإلتهاب الضرع هناء عبد المنعم عبد الفتاح عصفور ، سعاح فكرى درويش ، صفاء أبو العنين الوكيل

Email: hanaaasfour@yahoo.com Assiut University web-site: www.aun.edu.eg

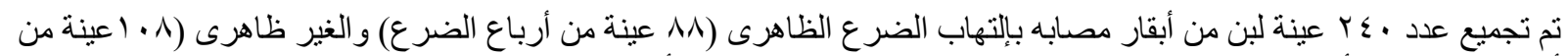

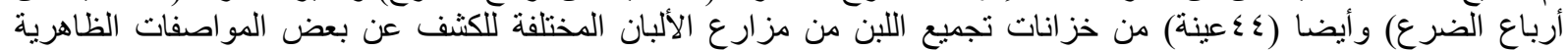

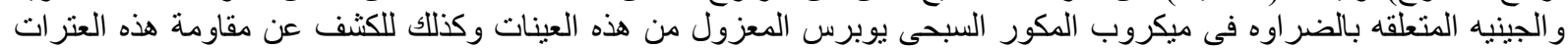

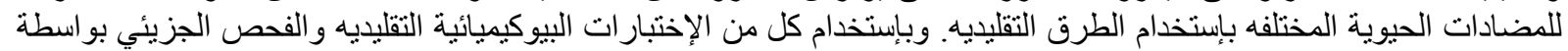

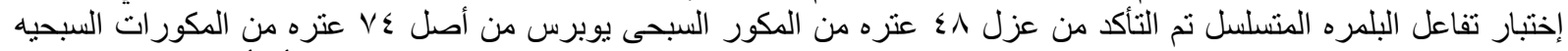

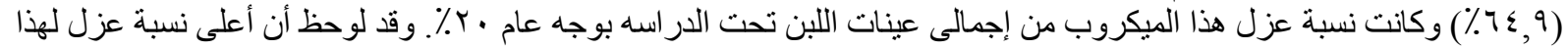

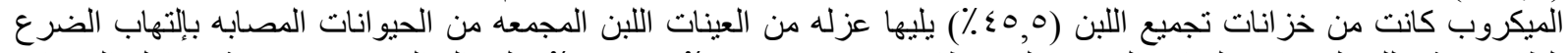

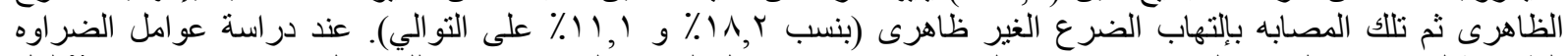

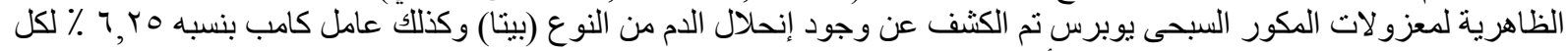

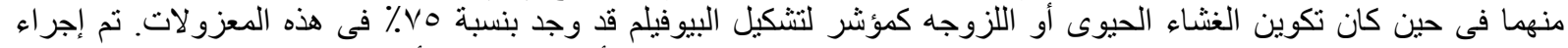

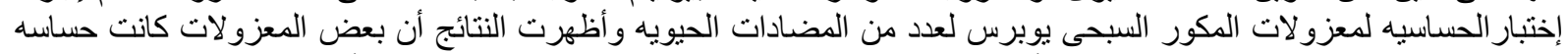

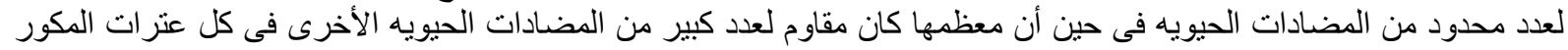

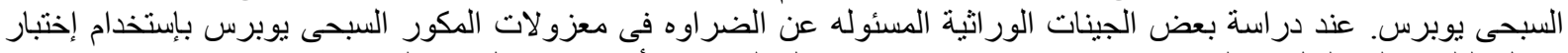

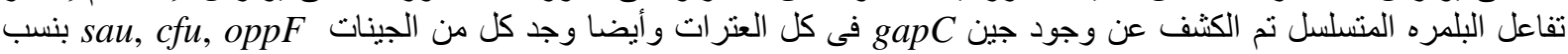

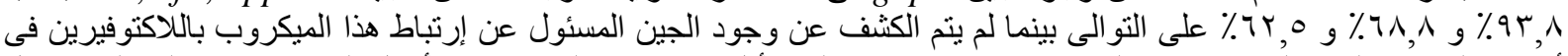

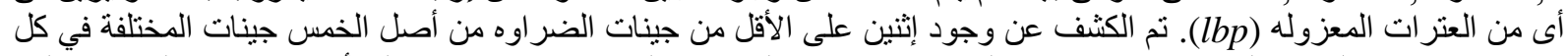

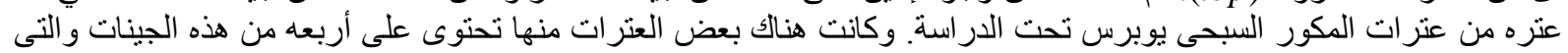

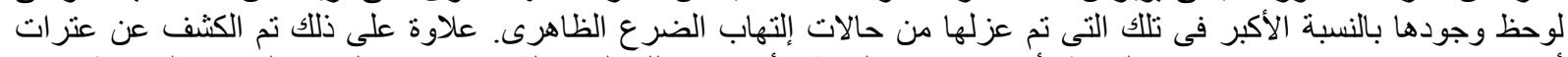

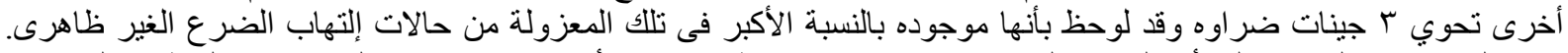

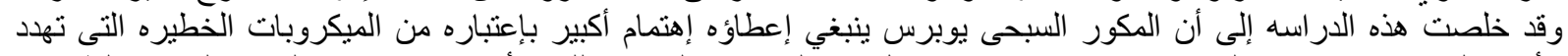

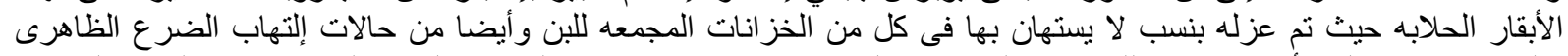

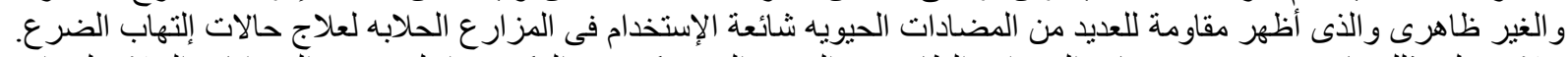

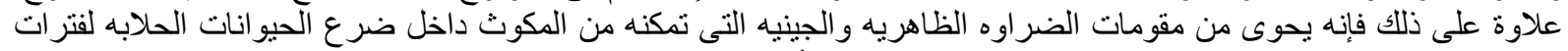

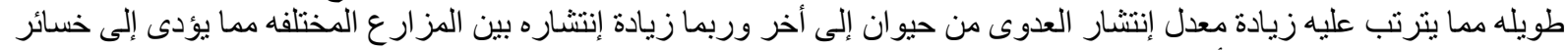
إقتصاديه كبيره فى صناعه الألبان. 